\title{
Physical activity and sedentary behaviour in European children: the IDEFICS study
}

\author{
Alba $M^{a}$ Santaliestra-Pasías ${ }^{1, *}$, Theodora Mouratidou', Vera Verbestel ${ }^{2}$, \\ Karin Bammann ${ }^{3}$, Dénes Molnar ${ }^{4}$, Sabina Sieri ${ }^{5}$, Alfonso Siani ${ }^{6}$, Toomas Veidebaum ${ }^{7}$, \\ Staffan Mårild ${ }^{8}$, Lauren Lissner ${ }^{9}$, Charalambos Hadjigeorgiou ${ }^{10}$, Lucia Reisch ${ }^{11}$, \\ Ilse De Bourdeaudhuij ${ }^{2}$ and Luis A Moreno', on behalf of the IDEFICS Consortium \\ ${ }^{1}$ GENUD (Growth, Exercise, Nutrition and Development) Research Group, School of Health Science (EUCS), \\ Department of Psychiatry and Nursing, University of Zaragoza, C/Domingo Miral s/n, 50009 Zaragoza, \\ Spain: ${ }^{2}$ Department of Movement and Sport Sciences, Ghent University, Ghent, Belgium: ${ }^{3}$ Department of \\ Biometry and Data Management, Bremen Institute for Prevention Research and Social Medicine (BIPS), Bremen \\ University, Bremen, Germany: ${ }^{4}$ Department of Pediatrics, Medical Faculty, University of Pécs, Pécs, Hungary: \\ ${ }^{5}$ Department of Preventive and Predictive Medicine, Nutritional Epidemiology Unit, Fondazione IRCCS, Istituto \\ Nazionale dei Tumori, Milan, Italy: 'Unit of Epidemiology and Population Genetics, Institute of Food Sciences, \\ National Research Council, Avellino, Italy: ${ }^{7}$ National Institute for Health Development, Center of Health and \\ Behavioral Sciences, Tallinn, Estonia: ${ }^{8}$ Department of Paediatrics, The Queen Silvia Children's Hospital, \\ University of Gothenburg, Gothenburg, Sweden: ${ }^{9}$ Department of Public Health and Community Medicine, Public \\ Health Epidemiology Unit, Sahlgrenska Academy, University of Gothenburg, Gothenburg, Sweden: ${ }^{10}$ Research \\ and Education Institute of Child Health, Nicosia, Cyprus: "'Department of Intercultural Communication and \\ Management, Copenhagen Business School, Frederiksberg, Denmark
}

Submitted 12 September 2012: Final revision received 2 August 2013: Accepted 7 August 2013: First published online 8 0ctober 2013

\begin{abstract}
Objective: To estimate the prevalence of physical activity and sedentary behaviours in European children, and to evaluate the relationship between media availability in personal space and physical activity in relation to total screen time.

Design: Data from the baseline IDEFICS (Identification and prevention of dietaryand lifestyle-induced health effects in children and infants) cross-sectional survey. Information on hours of television/digital video disk/video viewing and computer/ games-console use (weekday and weekend days), media device availability in personal space, sports club membership, hours of active organized play and commuting (to and from school) were assessed via a self-reported parental questionnaire. Total screen time was defined as the sum of daily media use and subsequently dichotomized into meeting or not meeting the guidelines of the American Academy of Pediatrics.

Setting: Eight survey centres (Italy, Estonia, Cyprus, Belgium, Sweden, Germany, Hungary and Spain).

Subjects: Children ( $n$ 15330; 51\% males) aged 2-10 years.

Results: Percentage of children engaged in total screen time for $>2 \mathrm{~h} / \mathrm{d}$ was higher on weekend days ( $52 \%$ v. $20 \%$ on weekdays) and in the older group ( $71 \%$ in males; $57 \%$ in females), varying by country. Children with a television set in their bedroom were more likely not to meet the screen time recommendations $(\mathrm{OR}=1 \cdot 54 ; 95 \%$ CI 1.60, 1.74).

Conclusions: Approximately a third of the children failed to meet current screen time recommendations. Availability of a television set in personal space increased the risk of excess total screen time. This information could be used to identify potential targets for public health promotion actions of young population groups.
\end{abstract}

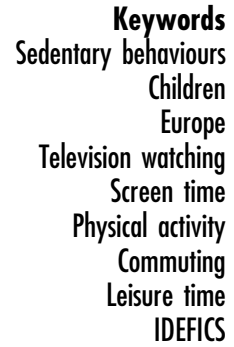

Increasing levels of physical inactivity and sedentarism in young population groups are observed in several developed countries ${ }^{(1,2)}$. Sedentary time is often defined as the time spent on specific sedentary behaviours such as television (TV) viewing or games-console use ${ }^{(3)}$.
The American Academy of Paediatrics (AAP) recommends parents to limit total media time exposure to no more than $1-2 \mathrm{~h} / \mathrm{d}^{(4)}$; however, an increasing proportion of children and adolescents do not meet the recommendations in several countries ${ }^{(2,5,6)}$. 
The relationship between physical activity (PA) and TV viewing is close to zero ${ }^{(7)}$ suggesting adequate day time for both activities. A large number of studies focus on TV viewing making it one of the most commonly examined sedentary behaviours ${ }^{(3,8)}$, although it might not necessarily reflect overall sedentary time ${ }^{(9)}$. Different patterns of PA and sedentary behaviours have been observed by age, gender and country ${ }^{(2,5,6)}$. For instance, the Health Behaviour in School-aged Children (HBSC) Study described such behaviours in a population of 11-15-year-olds, showing a high prevalence of sedentary time (61\% exceeded screen time recommendations) and lower time spent in PA $(<26 \%$ spent at least $1 \mathrm{~h} / \mathrm{d}$ in moderate-to-vigorous $\mathrm{PA})^{(5)}$. Moreover, greater accessibility to media sources in personal space was related to increased time spent in screen-viewing behaviours ${ }^{(6)}$. In addition, capturing non-school time PA and commuting could serve as potential indicators of PA given the growing evidence suggesting a positive relationship between these measures ${ }^{(10-12)}$.

Sedentary behaviour is an independent risk factor for chronic diseases such as the metabolic syndrome or $\mathrm{CVD}^{(13)}$, and during childhood has been associated with increased risk of overweight and obesity ${ }^{(2)}$. The effect of sedentary behaviour builds up over the course of childhood $^{(14)}$, making early adolescence an important life transition period. Children engaging in sports are more likely to be physically active during adolescence and adulthood $^{(15)}$ and to have a lower cardio-metabolic risk factors profile ${ }^{(16)}$. The aims of the present study were to: (i) estimate the prevalence of sedentary behaviours (TV/digital video disk (DVD)/video viewing, use of computer/games console, total screen time), electronic media availability in personal space and several PA variables in young children from eight European countries; (ii) describe regional-, country-, age- and sex-specific variations; (iii) assess the association between total screen time and media availability; and (iv) assess the association between total screen time and PA behaviours. In addition, the cumulative influence of total screen time could offer evidence to support effective prevention strategies aiming at reducing sedentary behaviour and increasing PA.

\section{Methods}

IDEFICS (Identification and prevention of dietary- and lifestyle-induced health effects in children and infants) is a community intervention study aiming to prevent obesity $^{(17,18)}$. The baseline survey, a multi-centre crosssectional study of children aged 2 to $<10$ years from eight European countries (Italy, Estonia, Cyprus, Belgium, Sweden, Hungary, Germany and Spain), is the focus of the present paper. Between September 2007 and June 2008, 16864 children were recruited and approximately $96 \%$ fulfilled the inclusion criteria (complete information on sex, height and weight). Participants were classified into two age groups: 2 to $<6$ years (pre-school children) and 6 to $<10$ years (schoolchildren).

The study was approved by the Research Ethics Committees in each centre involved. Parents or guardians provided written informed consent. Detailed operational study procedures are described elsewhere ${ }^{(17-19)}$.

\section{Data collection}

\section{Sociodemographic data}

Information on demographic factors was collected by a standardized self-reported parental questionnaire including children's gender, age, country and parental educational level. The International Standard Classification of Education (ISCED) index was used to classify parental educational level $^{(20)}$ and was used as a proxy indicator of socioeconomic status (SES) in subsequent analyses.

\section{Physical activity and sedentary behaviours}

The parental questionnaire was used to obtain information on children's PA and sedentary behaviours. Parents reported hours of TV/DVD/video viewing and computer/ games-console use both for a typical weekday and weekend days. Response categories included: (i) not at all; (ii) $<0.5 \mathrm{~h} / \mathrm{d}$; (iii) $<1 \mathrm{~h} / \mathrm{d}$; (iv) between 1 and $<2 \mathrm{~h} / \mathrm{d}$; (v) between 2 and $<3 \mathrm{~h} / \mathrm{d}$; and (vi) $>3 \mathrm{~h} / \mathrm{d}$. For the purposes of the current analysis, children's daily TV/DVD/ video and computer/games-console use were summed to obtain the total screen time per day (total hours per day, during weekdays, weekend days and the whole week). Thereafter, participants were classified into two groups according to the AAP's guidelines on total screen time: $\leq 2 \mathrm{~h} / \mathrm{d}$ and $>2 \mathrm{~h} / \mathrm{d}^{(4)}$. In 2-5-year-olds and 6-10-year-olds, low correlations were found between accelerometerderived sedentary time and parental-reported screen time in both age groups (Spearman $r=0.09, P<0.001$ for age 2-5 years; Spearman $r=0.03$ for age $6-10$ years; V Verbestel, S De Henauw, K Bammann et al., unpublished results). The parents also completed a question on media availability (i.e. TV, computer, etc.) in the child's personal space (e.g. bedroom).

PA was obtained by the sum of hours that children spent playing outdoors (weekdays and weekend days) and weekly participation in sports club activities for a typical week in the previous month. Total PA was calculated with the following formula: [(PA playing outdoors on weekdays $\times 5)+($ PA playing outdoors on weekend days $\times 2$ ) + weekly sports participation]/7. The time children spent playing outside was assessed using an outdoor playtime measure, which significantly correlated with objective measures of PA in pre-school children in a previous study $(r=0 \cdot 20, P=0 \cdot 003)^{(11)}$.

In the IDEFICS study, children's weekly participation in sports club activities was significantly correlated with children's daily time spent in moderate-to-vigorous PA as measured by an accelerometer. In 2-5- and 6-10-year-olds, 
a positive relationship was found between parental-reported sports participation and accelerometer-derived moderateto-vigorous PA (Spearman $r=0.14, \quad P<0.001$ for age 2-5 years; Spearman $r=0 \cdot 15, P<0 \cdot 001$ for 6-10-year-olds; V Verbestel, S De Henauw, K Bammann et al., unpublished results). Commuting to and from school were classified into three categories: (i) active commuting (walking or cycling); (ii) passive commuting (bus or car); and (iii) both (combination of active and passive commuting).

\section{Statistical analysis}

The Predictive Analytics SoftWare version $18 \cdot 0$ was used to analyse the data. Descriptive statistics of PA and sedentary behaviour variables stratified by age group, sex and country were computed using descriptive procedures. The $\chi^{2}$ test was used to compare PA and sedentary behaviours by sex. Binary logistic regression analyses with adjusted odds ratios (and 95\% confidence intervals) were used to examine the independent association between each variable and total screen time $(>2 \mathrm{~h} / \mathrm{d})$. In addition, multiple logistic regression with adjusted odds ratios (and 95\% confidence intervals) was performed to examine the cumulative association between all independent variables and total screen time $(>2 \mathrm{~h} / \mathrm{d})$, resulting in four prediction models. Adjustments were made for age and gender, SES and country. The first model examined the association between total screen time and individual media availability in personal space; the second model assessed the association between total screen time and cumulative media availability; the third model examined the association between total screen time and individual PA variables; and the fourth model examined the association between total screen time and cumulative PA variables.

\section{Results}

Complete data on PA and sedentary behaviours patterns from 15330 (94\% of the original sample) participants were obtained ( $51 \%$ males). Approximately $45 \%$ of the children in both gender groups were classified in the $<6$ years age category. Table 1 presents descriptive data on PA and sedentary behaviours by sex. Additionally, Table A (online supplementary material) presents aggregated descriptive information for excessive media use by country and sex. Descriptive results on SES, PA and sedentary behaviour by sex and country are presented for younger (Table 2) and older children (Table 3) separately. Overall, characteristics on PA and sedentary behaviours were similar between males and females within countries and age groups.

\section{Sedentary bebaviours}

Television/digital video disk/video viewing

Older males and females in Cyprus had the highest percentage of $\mathrm{TV} / \mathrm{DVD} /$ video viewing time $>2 \mathrm{~h} / \mathrm{d}$ during weekdays (21\% and 17\%, respectively) and weekend days (59\% and 56\%, respectively; see Table 3). Similarly, the younger males and females in Cyprus had higher percentage of TV/DVD/video viewing time $>2 \mathrm{~h} / \mathrm{d}$ during weekdays (19\% and 18\%, respectively) and weekend days (46\% and $41 \%$, respectively; see Table 2).

Older Swedish and Spanish males, and older Swedish females had the lowest percentage of TV/DVD/video viewing time $>2 \mathrm{~h} / \mathrm{d}$ during weekdays $(6 \cdot 1 \%$ in both cases for males, $4.0 \%$ for females). Older German males and Italian females had the lowest percentage of TV/DVD/video viewing time during weekend days (33\% in both cases; see Table 3). Younger Swedish males and females had the lowest percentage of TV/DVD/video viewing $>2 \mathrm{~h} / \mathrm{d}$ during weekdays $(3.6$ and $2.4 \%$, respectively) and younger Swedish males and German females had the lowest percentage during weekend days (22\% and 19\%, respectively; see Table 2).

\section{Computer/games-console use}

Highest electronic media use $(>2 \mathrm{~h} / \mathrm{d})$ was observed during weekend days in older Estonian males and females (23\% and 6.2\%, respectively; see Table 3). Lowest electronic media use was observed in younger Spanish males and Cypriot, Belgian and Swedish females (0\% in all groups; see Table 2 ).

\section{Total screen time}

Twenty-nine per cent of the participants did not meet the AAP recommendations. Figure 1 shows the proportion of children having weekly total screen time on average $>2 \mathrm{~h} / \mathrm{d}$ by gender, age and country. In all countries, higher percentage of exceeding total screen time was observed in older males followed by older females and younger males and females (Fig. 1). In addition, higher percentage of total screen time $>2 \mathrm{~h} / \mathrm{d}$ was more common during weekend days as opposed to weekdays (Tables 2 and 3).

\section{Media device availability}

Media device availability in personal space was observed in approximately a third of the sample; $71 \%$ of the total sample reported non-availability (66\% in males and $75 \%$ in females). Highest reported media availability in personal space was observed in Italy, where the majority of males (younger 73\%; older 81\%) and females (younger 65\%; older $76 \%$ ) had media devices available (Tables 2 and 3).

\section{Physical activity}

\section{Physical activity and sports club participation}

In most countries, older children were more physically active than the younger ones. A high proportion of males were members of sport clubs, mainly in Sweden and Estonia (75\% and $72 \%$, respectively, for older children). Great variability between countries in sports 
Table 1 Description of media use and availability and physical activity practice by sex among 15330 children aged 2-10 years in eight European countries; IDEFICS (Identification and prevention of dietary- and lifestyle-induced health effects in children and infants) study, September 2007-June 2008

\begin{tabular}{|c|c|c|c|}
\hline & Males & Females & $P$ value* \\
\hline \multicolumn{4}{|l|}{ Media use } \\
\hline \multicolumn{4}{|c|}{ TV/DVD/video viewing (\%) } \\
\hline \multicolumn{4}{|c|}{ Weekdays } \\
\hline$>2 \mathrm{~h} / \mathrm{d}$ & $11 \cdot 3$ & $9 \cdot 7$ & $<0.001$ \\
\hline \multicolumn{4}{|l|}{ Weekend days } \\
\hline$>2 \mathrm{~h} / \mathrm{d}$ & $39 \cdot 8$ & $36 \cdot 7$ & $<0.001$ \\
\hline \multicolumn{4}{|c|}{ Computer/games-console use (\%) } \\
\hline \multicolumn{4}{|l|}{ Weekdays } \\
\hline$>2 \mathrm{~h} / \mathrm{d}$ & $1 \cdot 3$ & 0.4 & $<0.001$ \\
\hline \multicolumn{4}{|l|}{ Weekend days } \\
\hline$>2 \mathrm{~h} / \mathrm{d}$ & $6 \cdot 6$ & $2 \cdot 1$ & $<0.001$ \\
\hline \multicolumn{4}{|c|}{ Total screen timet (\%) } \\
\hline \multicolumn{4}{|l|}{ Weekdays } \\
\hline$>2 \mathrm{~h} / \mathrm{d}$ & $24 \cdot 5$ & $16 \cdot 2$ & $<0.001$ \\
\hline \multicolumn{4}{|l|}{ Weekend days } \\
\hline$>2 \mathrm{~h} / \mathrm{d}$ & $57 \cdot 3$ & $47 \cdot 9$ & $<0.001$ \\
\hline \multicolumn{4}{|l|}{ Whole week } \\
\hline$>2 \mathrm{~h} / \mathrm{d}$ & $33 \cdot 5$ & $25 \cdot 0$ & $<0.001$ \\
\hline \multicolumn{4}{|l|}{ Media availability } \\
\hline \multicolumn{4}{|c|}{ No. of media devices in personal space (\%) } \\
\hline 0 & $58 \cdot 2$ & $62 \cdot 7$ & $<0.001$ \\
\hline 1 or 2 & $29 \cdot 0$ & $28 \cdot 5$ & \\
\hline $3+$ & $12 \cdot 8$ & $8 \cdot 8$ & \\
\hline \multicolumn{4}{|l|}{ Physical activity } \\
\hline \multicolumn{4}{|l|}{ Physical activity $¥$ (\%) } \\
\hline$\leq 2 \mathrm{~h} / \mathrm{d}$ & $61 \cdot 7$ & $58 \cdot 2$ & $<0.001$ \\
\hline \multicolumn{4}{|c|}{ Child member of sports club (\%) } \\
\hline Yes & $42 \cdot 3$ & 44.5 & $<0.001$ \\
\hline \multicolumn{4}{|c|}{ Time spent in sports club (\%) } \\
\hline$<1 \mathrm{~h} /$ week & $82 \cdot 1$ & $83 \cdot 7$ & $<0.001$ \\
\hline$\geq 1$ to $<4 \mathrm{~h} /$ week & $8 \cdot 0$ & $8 \cdot 3$ & \\
\hline$\geq 4 \mathrm{~h} /$ week & $9 \cdot 9$ & $8 \cdot 1$ & \\
\hline \multicolumn{4}{|c|}{ Transport (home-school)§ (\%) } \\
\hline Active & $28 \cdot 3$ & $28 \cdot 7$ & 0.599 \\
\hline Both & $54 \cdot 6$ & $54 \cdot 8$ & \\
\hline Passive & $17 \cdot 1$ & $16 \cdot 6$ & \\
\hline
\end{tabular}

TV, television; DVD, digital video disk.

*Gender differences using the Pearson $\chi^{2}$ test.

†Total screen time: total number of hours usually spent watching TV, videos or DVD and playing on the computer or games console. ¥Physical activity: sum of hours that children spent playing outdoors (weekdays and weekend days) and weekly participation in sports club activities.

§Transport: active, children go to and from school by walking or cycling; passive, children go to and from school by bus or car; both, one way as active transport and the other as passive transport.

club membership was observed in both males $(10 \%$ in younger Hungarian to $75 \%$ in older Swedish) and females ( $11 \%$ in younger Hungarian to $80 \%$ in older Swedish). The majority of children spent $<1 \mathrm{~h} /$ week participating in a sports club, both in males ( $82 \%$ in the younger group and $50 \%$ in the older group) and females (75\% and $53 \%$ in the younger and older group, respectively; Tables 2 and 3).

\section{Commuting to and from school}

The highest percentages of active commuting were observed in older German males and females (51\% and $55 \%$, respectively), and both in young and old Spanish males (54\% and 68\%, respectively) and females (54\% and $64 \%$, respectively). The lowest percentages were observed in Cypriot, Italian and Belgian participants of both genders (Tables 2 and 3).

\section{Association between total screen time and availability of media devices}

Table 4 presents the results of the logistic regression analyses for the total sample, separately for weekdays, weekend days and the whole week. The adjusted association between excess total screen time $(>2 \mathrm{~h} / \mathrm{d})$ and individual media availability is described in model 1 (Table 4) and between cumulative media availability variables is presented in model 2 (Table 4). Presence of individual media devices in personal space increased the odds of having $>2 \mathrm{~h} / \mathrm{d}$ total screen time. The highest effect during weekdays, weekend days and the whole week was observed in those having a PlayStation/games console $(\mathrm{OR}=2 \cdot 41 ; 95 \%$ CI $2 \cdot 12, \quad 2 \cdot 75 ; \quad \mathrm{OR}=2 \cdot 20$; $95 \%$ CI $1 \cdot 92,2 \cdot 52 ;$ and $\mathrm{OR}=2 \cdot 40 ; 95 \%$ CI $2 \cdot 11,2 \cdot 72$, respectively) in their personal space. In model 2 , the effects changed with the addition of predicting variables. 
Table 2 Media use and availability and physical activity practice of younger children ( 2 to $<6$ years old) in eight European countries stratified by sex; IDEFICS (Identification and prevention of dietary- and lifestyle-induced health effects in children and infants) study, September 2007-June 2008

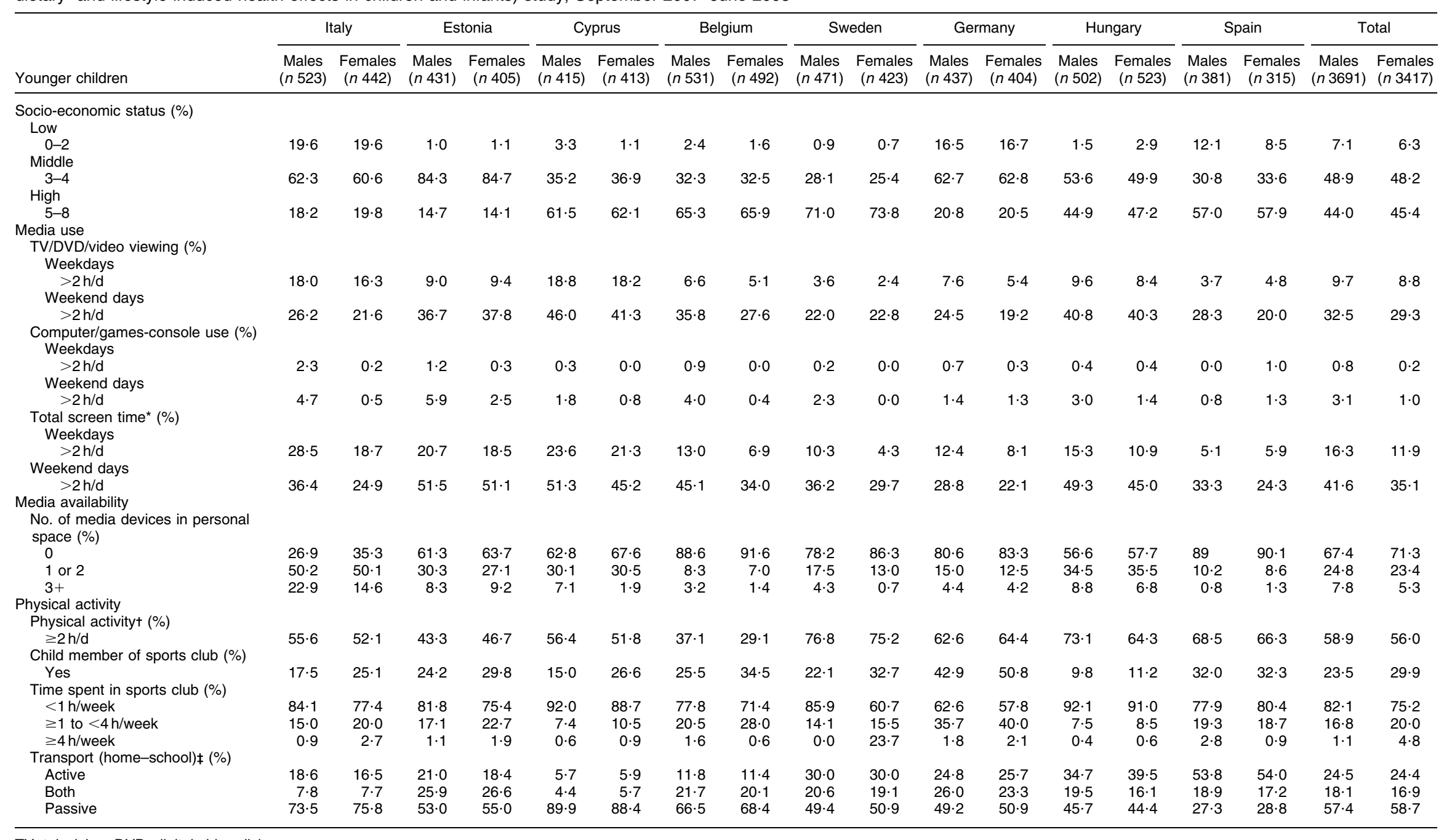

TV, television; DVD, digital video disk.

*Total screen time: total number of hours usually spent watching TV, videos or DVD and playing on the computer or games console.

tPhysical activity: sum of hours that children spent playing outdoors (weekdays and weekend days) and weekly participation in sports club activities.

$\ddagger$ Transport: active, children go to and from school by walking or cycling; passive, children go to and from school by bus or car; both, one way as active transport and the other as passive transport. 
Table 3 Media use and availability and physical activity practice of older children ( 6 to $<10$ years old) in eight European countries stratified by sex; IDEFICS (Identification and prevention of dietary- and lifestyle-induced health effects in children and infants) study, September 2007-June 2008

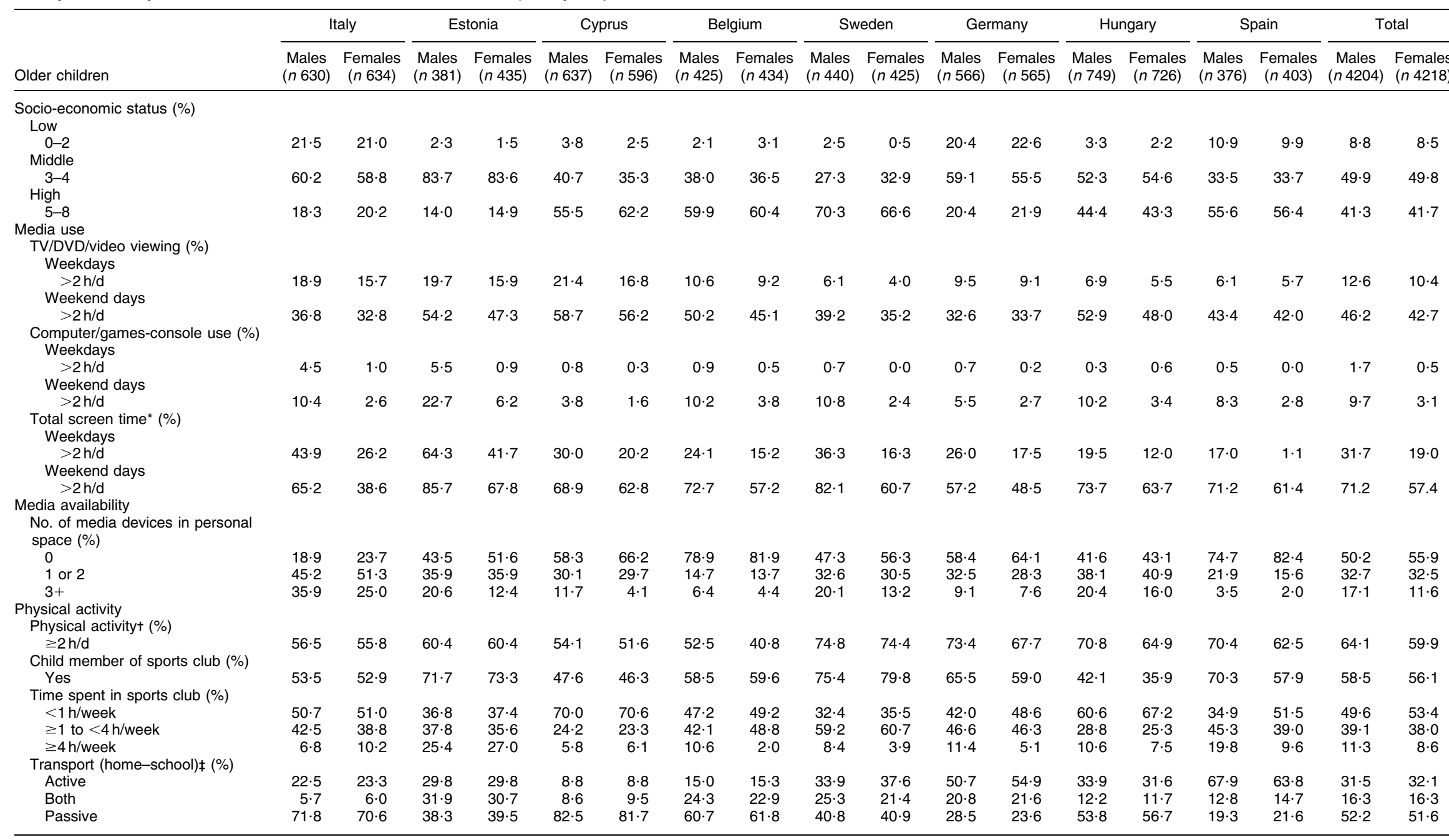

TV, television; DVD, digital video disk.

*Total screen time: total number of hours usually spent watching TV, videos or DVD and playing on the computer or games console.

tPhysical activity: sum of hours that children spent playing outdoors (weekdays and weekend days) and weekly participation in sports club activities.

‡Transport: active, children go to and from school by walking or cycling; passive, children go to and from school by bus or car; both, one way as active transport and the other as passive transport. 


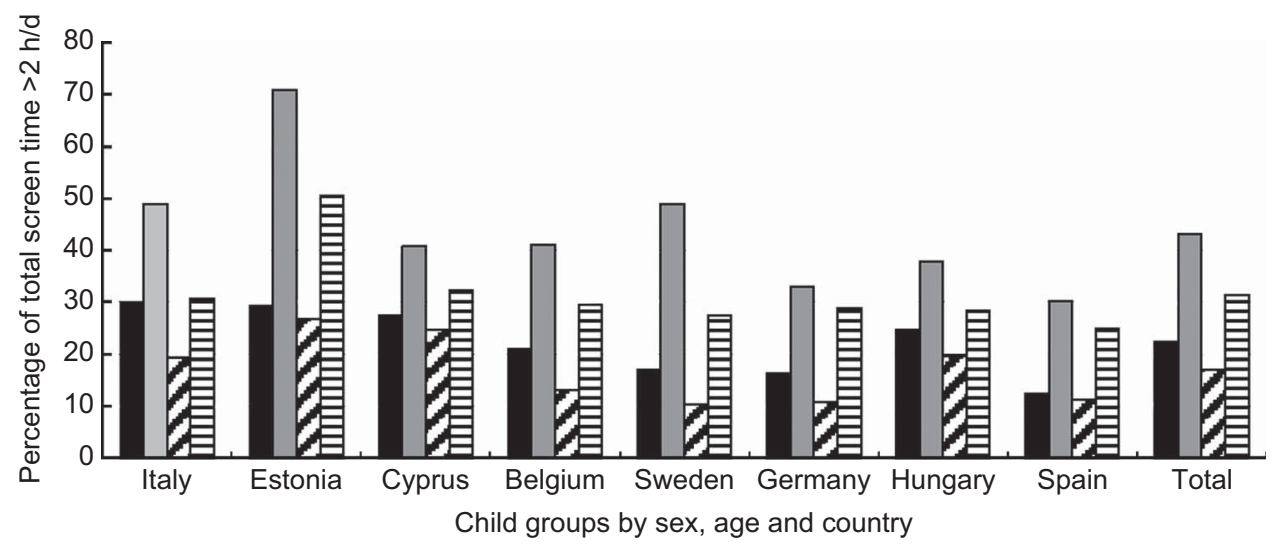

Fig. 1 Prevalence of weekly total screen time viewing $>2 \mathrm{~h} / \mathrm{d}$ among 15330 children in eight European countries by sex and age group ( $\square$, younger males ( 2 to $<6$ years old); $\square$, older males ( 6 to $<10$ years old); $\square$, younger females ( 2 to $<6$ years old); $\boxminus$, older females ( 6 to $<10$ years old); IDEFICS (Identification and prevention of dietary- and lifestyle-induced health effects in children and infants) study, September 2007-June 2008

Children with a TV in their personal space were more likely to have a total screen time of $>2 \mathrm{~h} / \mathrm{d}$ during weekdays (OR $=1 \cdot 48 ; 95 \%$ CI 1.30, 1.69), weekend days $(\mathrm{OR}=1.58 ; 95 \% \mathrm{CI} 1 \cdot 40,1 \cdot 78)$ and the whole week $(\mathrm{OR}=1 \cdot 54 ; 95 \%$ CI 1.60, 1.74), whereas those having a computer or PlayStation/games console were less likely to have $>2 \mathrm{~h} / \mathrm{d}$ of total screen time (19\% and $44 \%$ during weekdays; $16 \%$ and $38 \%$ during weekend days; and $21 \%$ and $44 \%$ during the whole week, respectively; Table 4 , model 2).

\section{Association between total screen time and physical activity}

Model 3 (Table 5) describes the adjusted association between total screen time $(>2 \mathrm{~h} / \mathrm{d})$ and individual PA variables, separately for weekdays and weekend days and stratified by age group. Sports club membership increased the odds of having $>2 \mathrm{~h} / \mathrm{d}$ total screen time (OR $=1 \cdot 17$; $95 \%$ CI $1 \cdot 07,1 \cdot 27$ ), while passive commuting was associated with decreased total screen time $(\mathrm{OR}=0 \cdot 77$; $95 \%$ CI $0 \cdot 69,0 \cdot 85)$. The effects changed with the inclusion of all variables in model 4 (Table 5). The only remaining significant factor was passive commuting, associated with a $23 \%$ lower likelihood of total screen time of $>2 \mathrm{~h} / \mathrm{d}$.

\section{Discussion}

The aim of the present study was to describe the prevalence of PA and sedentary behaviours in children participating in the IDEFICS study stratified by age, gender and country. To the authors' knowledge, the present study is the first one to provide comparable information on PA and sedentary behaviours, combined with media availability, in children aged 2-10 years old in different European countries. The study provides very rich data for understanding the screen-related sedentary behaviours among European children. The AAP recommends media time exposure of $\leq 2 \mathrm{~h} / \mathrm{d}$ for mitigating negative health effects in youth people ${ }^{(4)}$. The main finding of our study was the proportion of children not meeting the AAP recommendation for media time, which was $29 \%$ (33\% of males and $25 \%$ of females), more evident during weekend days. Another major finding of our study was the high proportion of older participants failing to meet the AAP screen time recommendations ( $43 \%$ of males and $31 \%$ of females). No comparable information on compliance to total screen time recommendations in children or adolescents was identified in multi-national studies. Subsequently, comparisons with other studies are made on the basis of the most widely assessed sedentary behaviour, i.e. TV viewing. The HBSC Study $^{(5)}$ observed that $61 \%$ of children aged $11-15$ years watched TV for $>2 \mathrm{~h} / \mathrm{d}$. In adolescents aged 12.5 to $17 \cdot 5$ years participating in the Healthy Lifestyle in Europe by Nutrition in Adolescence (HELENA) study, the proportion who watched TV for more than $2 \mathrm{~h} / \mathrm{d}$ during weekend days was $58 \%$ in males and $53 \%$ in females ${ }^{(6)}$. Evidence suggests that adolescence is the period during which the highest proportion fails to meet the screen time recommendation; therefore early age evidence could inform intervention strategies before levels of sedentary behaviours increase, i.e. in the transition period from childhood to adolescence. Another important finding of our study was the high proportion of older participants not meeting screen time recommendations during weekend days ( $71 \%$ of males and $57 \%$ of females). Previous research has also suggested higher screenviewing time in older children ${ }^{(21)}$. We also observed a high proportion of males watching TV in excess, unlike in three reviews with a variety of age groups which reported no gender differences ${ }^{(3,8,22)}$. Large variations for computer/games-console use between countries, such as older Estonian females $v$. Swedish ones $(6 \cdot 2 \%$ and $0 \%$ 
Table 4 Prediction models of total screen time viewing ( $>2 \mathrm{~h} / \mathrm{d})$ and its association with media devices availability among 15330 children aged $2-10$ years in eight European countries; IDEFICS (Identification and prevention of dietary- and lifestyle-induced health effects in children and infants) study, September 2007-June 2008

\begin{tabular}{|c|c|c|c|c|c|c|c|c|c|c|c|c|}
\hline \multirow[b]{3}{*}{ Variable } & \multicolumn{10}{|c|}{ Model 1} & & \\
\hline & \multicolumn{2}{|c|}{ Model $1 \cdot 1$} & \multicolumn{2}{|c|}{ Model $1 \cdot 2$} & \multicolumn{2}{|c|}{ Model 1.3} & \multicolumn{2}{|c|}{ Model 1.4} & \multicolumn{2}{|c|}{ Model 1.5} & \multicolumn{2}{|c|}{ Model 2} \\
\hline & OR & $95 \% \mathrm{Cl}$ & OR & $95 \% \mathrm{Cl}$ & OR & $95 \% \mathrm{Cl}$ & OR & $95 \% \mathrm{Cl}$ & OR & $95 \% \mathrm{Cl}$ & OR & $95 \% \mathrm{Cl}$ \\
\hline \multicolumn{13}{|l|}{ TST weekdays } \\
\hline $\begin{array}{l}\text { No* } \\
\text { Computer }\end{array}$ & 1.96 & $1 \cdot 77,2 \cdot 17$ & - & & - & & - & & - & & $1 \cdot 48$ & $1 \cdot 30,1 \cdot 69$ \\
\hline $\begin{array}{l}\text { No* }^{*} \\
\text { Internet connection }\end{array}$ & - & & 1.59 & $1 \cdot 41,1 \cdot 78$ & - & & - & & - & & 0.81 & $0.71,0.94$ \\
\hline $\begin{array}{l}\mathrm{No}^{*} \\
\text { Video/DVD player }\end{array}$ & - & & - & & $1 \cdot 85$ & $1 \cdot 59,2 \cdot 16$ & - & & - & & 0.79 & $0.65,0.96$ \\
\hline $\begin{array}{l}\text { No* } \\
\text { PlayStation/games console }\end{array}$ & - & & - & & - & & $1 \cdot 81$ & $1 \cdot 62,2 \cdot 02$ & - & & 0.88 & $0 \cdot 76,1 \cdot 01$ \\
\hline $\begin{array}{l}\mathrm{No}^{*} \\
\text { TST weekend days } \\
\text { TV }\end{array}$ & - & & - & & - & & - & & $2 \cdot 41$ & $2 \cdot 12,2 \cdot 75$ & 0.56 & $0.48,0.64$ \\
\hline $\begin{array}{l}\mathrm{No}^{*} \\
\text { Computer }\end{array}$ & 1.95 & $1 \cdot 78,2 \cdot 14$ & - & & - & & - & & - & & 1.58 & $1 \cdot 40,1 \cdot 78$ \\
\hline $\begin{array}{l}\mathrm{No}^{*} \\
\text { Internet connection }\end{array}$ & - & & $1 \cdot 49$ & $1 \cdot 33,1 \cdot 66$ & - & & - & & - & & 0.84 & $0.73,0.96$ \\
\hline $\begin{array}{l}\text { No* }^{*} \\
\text { Video/DVD player }\end{array}$ & - & & - & & $1 \cdot 72$ & $1 \cdot 47,2.02$ & - & & - & & 0.83 & $0.68,1.01$ \\
\hline $\begin{array}{l}\text { No* }^{*} \\
\text { PlayStation/games console }\end{array}$ & - & & - & & - & & $1 \cdot 81$ & $1 \cdot 63,2 \cdot 00$ & - & & $0 \cdot 88$ & $0 \cdot 77,1 \cdot 00$ \\
\hline $\begin{array}{l}\mathrm{No}^{*} \\
\text { TST week }\end{array}$ & - & & - & & - & & - & & $2 \cdot 20$ & $1 \cdot 92,2 \cdot 52$ & 0.62 & $0 \cdot 52,0 \cdot 72$ \\
\hline $\begin{array}{l}\text { TV } \\
\text { No* } \\
\text { Computer }\end{array}$ & 1.97 & $1 \cdot 80,2 \cdot 17$ & - & & - & & - & & - & & 1.54 & $1 \cdot 60,1 \cdot 74$ \\
\hline $\begin{array}{l}\text { No* } \\
\text { Internet connection }\end{array}$ & - & & $1 \cdot 58$ & $1 \cdot 42,1 \cdot 76$ & - & & - & & - & & 0.79 & $0.69,0.90$ \\
\hline $\begin{array}{l}\mathrm{No}^{*} \\
\text { Video/DVD player }\end{array}$ & - & & - & & $1 \cdot 79$ & $1 \cdot 54,2 \cdot 07$ & - & & - & & $0 \cdot 84$ & $0 \cdot 70,1 \cdot 01$ \\
\hline $\begin{array}{l}\text { No* }^{*} \\
\text { PlayStation/games console }\end{array}$ & - & & - & & - & & $1 \cdot 81$ & $1 \cdot 63,2 \cdot 00$ & - & & $0 \cdot 89$ & $0 \cdot 78,1 \cdot 01$ \\
\hline $\mathrm{No}^{*}$ & - & & - & & - & & - & & $2 \cdot 40$ & $2 \cdot 11,2 \cdot 72$ & 0.56 & $0.49,0.65$ \\
\hline
\end{tabular}


Table 5 Prediction models of screen time viewing ( $>2 \mathrm{~h} / \mathrm{d}$ ) and its association with physical activity by age group among 15330 children aged $2-10$ years in eight European countries; IDEFICS (Identification and prevention of dietary- and lifestyle-induced health effects in children and infants) study, September 2007-June 2008

\begin{tabular}{|c|c|c|c|c|c|c|c|c|c|c|}
\hline \multirow[b]{3}{*}{ Variable } & \multicolumn{8}{|c|}{ Model 3} & & \\
\hline & \multicolumn{2}{|c|}{ Model $3 \cdot 1$} & \multicolumn{2}{|c|}{ Model $3 \cdot 2$} & \multicolumn{2}{|c|}{ Model $3 \cdot 3$} & \multicolumn{2}{|c|}{ Model 3.4} & \multicolumn{2}{|c|}{ Model 4} \\
\hline & OR & $95 \% \mathrm{Cl}$ & OR & $95 \% \mathrm{Cl}$ & OR & $95 \% \mathrm{Cl}$ & OR & $95 \% \mathrm{Cl}$ & OR & $95 \% \mathrm{Cl}$ \\
\hline \multicolumn{11}{|c|}{ TST weekdays in younger children ( 2 to $<6$ years old) } \\
\hline$\geq 2 \mathrm{~h} / \mathrm{d} t$ & 1.04 & $0.89,1 \cdot 22$ & - & & - & & - & & 1.04 & $0 \cdot 88,1 \cdot 24$ \\
\hline \multicolumn{11}{|l|}{ Member of sports club } \\
\hline Yest & - & & 1.26 & $1.04,1.53$ & - & & - & & 0.99 & $0 \cdot 65,1 \cdot 51$ \\
\hline \multicolumn{11}{|l|}{$\begin{array}{l}\text { Time spent in sports club } \\
\geq 4 \mathrm{~h} / \text { weekt }\end{array}$} \\
\hline$<1 \mathrm{~h} /$ week & - & & - & & $1 \cdot 16$ & $0.54,2 \cdot 29$ & - & & $1 \cdot 13$ & $0.48,2 \cdot 67$ \\
\hline$\geq 1$ to $<4 \mathrm{~h} /$ week & - & & - & & 0.85 & $0 \cdot 41,1 \cdot 78$ & - & & 0.89 & $0.41,1.96$ \\
\hline \multirow{2}{*}{\multicolumn{11}{|c|}{ Transport between home and school }} \\
\hline & & & & & & & & & & \\
\hline Passive & - & & - & & - & & 0.76 & $0.63,0.92$ & 0.73 & $0.59,0.89$ \\
\hline Both & - & & - & & - & & 0.72 & $0.56,0.93$ & 0.75 & $0.58,0.97$ \\
\hline \multicolumn{11}{|c|}{ TST weekdays in older children ( 6 to $<10$ years old) } \\
\hline \multicolumn{11}{|c|}{ Physical activity* } \\
\hline$\geq 2 \mathrm{~h} / \mathrm{dt}$ & $1 \cdot 07$ & $0.95,1 \cdot 20$ & - & & - & & - & & 1.05 & $0.93,1 \cdot 19$ \\
\hline \multicolumn{11}{|l|}{ Member of sports club } \\
\hline Yest & - & & 1.33 & $1 \cdot 18,1 \cdot 50$ & - & & - & & $1 \cdot 36$ & $0.98,1 \cdot 88$ \\
\hline \multicolumn{11}{|c|}{$\begin{array}{l}\text { Time spent in sports club } \\
\geq 4 \mathrm{~h} / \text { weekt }\end{array}$} \\
\hline$<1 \mathrm{~h} /$ week & - & & - & & $1 \cdot 41$ & $1 \cdot 16,1 \cdot 71$ & - & & 1.03 & $0 \cdot 72,1 \cdot 47$ \\
\hline$\geq 1$ to $<4 \mathrm{~h} /$ week & - & & - & & $1 \cdot 15$ & $0.95,1.40$ & - & & $1 \cdot 12$ & $0.92,1.37$ \\
\hline \multicolumn{11}{|c|}{ Transport between home and school } \\
\hline Passive & - & & - & & - & & 0.73 & $0.63,0.84$ & 0.72 & $0.62,0.83$ \\
\hline Both & _- & & - & & - & & 0.92 & $0.78,1.09$ & 0.89 & $0.74,1.06$ \\
\hline \multicolumn{11}{|c|}{ TST weekend days in younger children ( 2 to $<6$ years old) } \\
\hline \multicolumn{11}{|c|}{ Physical activity* ${ }^{*}$} \\
\hline$\geq 2 \mathrm{~h} / \mathrm{dt}$ & $1 \cdot 01$ & $0 \cdot 88,1 \cdot 15$ & - & & - & & - & & $1 \cdot 01$ & $0 \cdot 87,1 \cdot 17$ \\
\hline Member of sports club & & & & & & & & & & \\
\hline Yest & - & & 1.06 & $0.90,1.25$ & - & & - & & 0.93 & $0 \cdot 66,1 \cdot 32$ \\
\hline \multicolumn{11}{|c|}{$\begin{array}{l}\text { Time spent in sports club } \\
\geq 4 \text { lweekt }\end{array}$} \\
\hline$<1 \mathrm{~h} /$ week & - & & & & $1 \cdot 22$ & $0.63,2.35$ & - & & $1 \cdot 30$ & $0.61,2 \cdot 81$ \\
\hline$\geq 1$ to $<4 \mathrm{~h} /$ week & - & & - & & $1 \cdot 17$ & $0.60,2 \cdot 29$ & - & & $1 \cdot 16$ & $0 \cdot 57,2 \cdot 35$ \\
\hline \multirow{2}{*}{\multicolumn{11}{|c|}{ Transport between home and school }} \\
\hline Activet & & & & & & & & & & \\
\hline Passive & - & & - & & - & & 0.82 & $0.69,0.97$ & 0.79 & $0.66,0.94$ \\
\hline Both & - & & - & & - & & $0 \cdot 83$ & $0.67,1.03$ & 0.86 & $0.69,1.07$ \\
\hline
\end{tabular}


respectively), were found in our study. Similarly, country differences in TV watching and other sedentary behaviours have also been observed in another descriptive review ${ }^{(2)}$. In our study, regular engagement in sports was $43 \%$ ( $42 \%$ in males and $44 \%$ in females). In other studies with adolescents, low engagement in organized sports activities was observed $^{(1,15,23)}$ and our results could suggest that habit formation of PA may be important at early ages. In our sample, sports participation was higher in older children; these results are somehow to be expected since pre-school children do not normally participate regularly in organized PA. Our results in the older group (58\% in males and 56\% in females) were comparable to those observed in US children $(59 \%)^{(24)}$. Commuting to and from school was predominantly passive in the majority of the countries in the present study and in agreement with Fainardi et $a l .{ }^{(25)}$; it should be noted that active commuting might be related to SES, due to the results obtained by Hallal et al. ${ }^{(15)}$ who found active commuting to be more common to be among poor adolescents.

Our findings are consistent with those observed in other studies suggesting an association between the presence of media devices in personal space and increased risk of screen-related behaviours, such as having a TV or a games console in the bedroom being associated with higher TV viewing ${ }^{(6,26)}$. For example, findings from the HELENA study indicated that adolescents who had a computer in their bedroom were $43 \%$ less likely to have an excess of TV viewing ${ }^{(6)}$. Negative observed associations between the presence of other media devices and total screen time could be attributed to the fact that children spent a higher proportion of their sedentary time on TV/DVD/video viewing (81.62 (SD 18.9) \% of their total screen time; data not shown). A recent review, however, showed unclear associations among young children ${ }^{(27)}$. No relationships between screen-viewing time and level of PA were observed in our study, similarly to other studies assessing PA using objective methods ${ }^{(1,28)}$. Besides, a longitudinal study of children aged 10-15 years indicated no relationship between changes in TV viewing and changes in high-intensity leisure-time activities ${ }^{(29)}$. Moreover, frequency of total screen and TV viewing time were not associated with sports participation in Brazilian adolescents $^{(23)}$. Absence of such relationships could indicate other that factors potentially affect screen time, like other leisure activities. Very few reported studies have related screen-viewing time with active or passive commuting. Surprisingly, passive commuting was related with less total screen time in the current study. A higher proportion of passive commuting was reported in adolescents from higher SES backgrounds ${ }^{(30)}$, who are also suggested to be involved in more extracurricular activities $^{(31)}$. Therefore we hypothesize that time restraints due to increased commitments could explain our observations; i.e. children using passive commuting have more extra activities, and they use passive commuting 
as a means of arriving on time and subsequently spend less time on sedentary activities like total screen time. Additionally, a higher proportion of adolescent members of sports clubs used passive commuting as means of transport to and from school (data not shown). In contrast with our results, no relationship between passive commuting and total screen time was reported by Mota et al. ${ }^{(30)}$, supporting the fact that screen activities are generalized activities in youth.

The strengths of our study include the large sample of children from different European countries and the implementation of a harmonized methodology. The inclusion of other sedentary behaviours among children younger than 10 years like computer and games-console use is also strength of the study, as well as the assessment of other types of inactivity like passive commuting. In addition, the population included children from different age groups which allowed stratified analyses without loss of statistical power. The description of multiple indicators of PA and sedentary behaviours at the same time allowed us to provide a clearer picture of the current situation and to identify the most prevalent behaviours. Also, the presence of children from Southern, Western, Eastern and Northern countries offers the opportunity to have an overview at the European level. The study has some weaknesses. The inherent limitations of the cross-sectional design affect the assessment of the causal effect between total screen time and the specific PA and sedentary behaviours. Second, examined measures and associations were based on parental reports which might underestimate and misrepresent the prevalence of behaviours. Nevertheless, questionnaire use is the most common method to subjectively assess PA and sedentary behaviours and this is due mainly to the low cost and the ease of administration in a large European sample. In addition, PA was also reported via a questionnaire, which does not reflect objective measures of total $\mathrm{PA}^{(32)}$. However, it provides information about PA which is not available when using objective methods like accelerometry, i.e. type of sport. Another limitation of our study was the small number of children included in some groups, i.e. the high computer/ games-console use categories.

Our findings contribute to the literature by providing information on the prevalence of sedentary behaviours, media availability, commuting types to and from school, as well as the PA behaviours of European children stratified by age, gender and country; such information could be used to identify potential targets for public health promotion actions of young population groups. In addition, comparisons between weekdays and weekend days could be the key point in developing effective intervention strategies to reduce specific sedentary behaviours at weekdays or weekend days. Further internationally comparable studies are needed to confirm or contrast our findings. Concerted public health efforts are needed to decrease the amount of daily time spent in sedentary behaviours given its important health implications. Country-specific public health strategies could be implemented to encourage children to decrease specific sedentary behaviours and increase daily PA, with the purpose of meeting international recommendations for media time and improving overall lifestyle factors.

\section{Acknowledgements}

Sources of funding: This work was carried out as part of the IDEFICS study (www.idefics.eu), which is financially supported by the European Community within the Sixth RTD Framework Programme, Contract No. 016181 (FOOD). The European Community had no role in the design, analysis or writing of this article. Additionally, A.M.S.-P. received financial support from the Fundación Cuenca Villoro (Spain). Conflict of interest: There are no conflicts of interest to declare. Authors' contributions: A.M.S.-P. and T.M. had full access to all data in the study and take responsibility for the integrity of the data and the accuracy of the data analysis. Study concept and design: A.M.S.-P., T.M., K.B., L.L., I.D.B. and L.A.M. Statistical analysis: A.M.S.-P., T.M. and I.D.B. Analysis and interpretation of data: A.M.S.-P., T.M., V.V., K.B., D.M., S.S., A.S., T.V., S.M., L.L., C.H., L.R., I.D.B. and L.A.M. Critical revision of the manuscript for important intellectual content: A.M.S.-P., T.M., V.V., K.B., D.M., S.S., A.S., T.V., S.M., L.L., C.H., L.R., I.D.B. and L.A.M.

\section{Supplementary material}

To view supplementary material for this article, please visit http://dx.doi.org/10.1017/S1368980013002486

\section{References}

1. Ekelund U, Brage S, Froberg K et al. (2006) TV viewing and physical activity are independently associated with metabolic risk in children: the European Youth Heart Study. PLoS Med 3, e488.

2. Rey-Lopez JP, Vicente-Rodriguez G, Bueno G et al. (2011) Sedentary behaviors and obesity in children and adolescents. In Epidemiology of Obesity in Children and Adolescents: Prevalence and Etiology, pp. 367-376 [LA Moreno, I Pigeot and W Ahrens, editors]. New York: Springer Science.

3. Marshall SJ, Gorely T \& Biddle SJ (2006) A descriptive epidemiology of screen-based media use in youth: a review and critique. J Adolesc 29, 333-349.

4. American Academy of Pediatrics (2001) Children, adolescents, and television. Pediatrics 107, 423-426.

5. Currie C, Nic Gabhainn S, Godeau E et al. (2008) Inequalities in Young People's Health: Health Behaviour in School-aged Children (HBSC) Study; International Report from the 2005/ 2006 Survey. Health Policy for Children and Adolescents no. 5. Copenhagen: WHO Regional Office for Europe.

6. Rey-Lopez JP, Vicente-Rodriguez G, Ortega FB et al. (2010) Sedentary patterns and media availability in European adolescents: the HELENA study. Prev Med 51, 50-55. 
7. Marshall SJ, Biddle SJ, Gorely T et al. (2004) Relationships between media use, body fatness and physical activity in children and youth: a meta-analysis. Int J Obes Relat Metab Disord 28, 1238-1246.

8. Hinkley T, Salmon J, Okely AD et al. (2010) Correlates of sedentary behaviours in preschool children: a review. Int $\mathrm{J}$ Behav Nutr Phys Act 7, 66.

9. Biddle SJ, Gorely T \& Marshall SJ (2009) Is television viewing a suitable marker of sedentary behavior in young people? Ann Behav Med 38, 147-153.

10. Owen CG, Nightingale CM, Rudnicka AR et al. (2012) Travel to school and physical activity levels in 9-10 year-old UK children of different ethnic origin; Child Heart and Health Study in England (CHASE). PLOS One 7, e30932.

11. Burdette HL, Whitaker RC \& Daniels SR (2004) Parental report of outdoor playtime as a measure of physical activity in preschool-aged children. Arch Pediatr Adolesc Med 158, 353-357.

12. Chillon P, Ortega FB, Ruiz JR et al. (2011) Active commuting and physical activity in adolescents from Europe: results from the HELENA study. Pediatr Exerc Sci 23, 207-217.

13. Hamilton MT, Hamilton DG \& Zderic TW (2007) Role of low energy expenditure and sitting in obesity, metabolic syndrome, type 2 diabetes, and cardiovascular disease. Diabetes 56, 2655-2667.

14. Hancox RJ \& Poulton R (2006) Watching television is associated with childhood obesity: but is it clinically important? Int J Obes (Lond) 30, 171-175.

15. Hallal PC, Wells JC, Reichert FF et al. (2006) Early determinants of physical activity in adolescence: prospective birth cohort study. BMJ 332, 1002-1007.

16. Jago R, Wedderkopp N, Kristensen PL et al. (2008) Six-year change in youth physical activity and effect on fasting insulin and HOMA-IR. Am J Prev Med 35, 554-560.

17. Ahrens W, Bammann K, de Henauw S et al. (2006) Understanding and preventing childhood obesity and related disorders - IDEFICS: a European multilevel epidemiological approach. Nutr Metab Cardiovasc Dis 16, 302-308.

18. Bammann K, Peplies J, Sjöström M et al. (2006) Assessment of diet, physical activity and biological, social and environmental factors in a multi-centre European project on diet- and lifestyle-related disorders in children (IDEFICS). J Public Health 14, 279-289.

19. Ahrens W, Bammann K, Siani A et al. (2011) The IDEFICS cohort: design, characteristics and participation in the baseline survey. Int J Obes (Lond) 35, Suppl. 1, S3-S15.
20. United Nations Educational, Scientific and Cultural Organization (2010) ISCED: International Standard Classification of Education. http://www.uis.unesco.org/Education/ Pages/international-standard-classification-of-education.aspx (accessed April 2012).

21. Hoyos Cillero I, Jago R \& Sebire S (2011) Individual and social predictors of screen-viewing among Spanish school children. Eur J Pediatr 170, 93-102.

22. Gorely T, Marshall SJ \& Biddle SJ (2004) Couch kids: correlates of television viewing among youth. Int J Behav Med 11, 152-163.

23. Fernandes RA, Junior IF, Cardoso JR et al. (2008) Association between regular participation in sports and leisure time behaviors in Brazilian adolescents: a crosssectional study. BMC Public Health 8, 329.

24. Singh GK, Yu SM, Siahpush M et al. (2008) High levels of physical inactivity and sedentary behaviors among US immigrant children and adolescents. Arch Pediatr Adolesc Med 162, 756-763.

25. Fainardi V, Scarabello C, Brunella I et al. (2009) Sedentary lifestyle in active children admitted to a summer sport school. Acta Biomed 80, 107-116.

26. He M, Harris S, Piche L et al. (2009) Understanding screenrelated sedentary behavior and its contributing factors among school-aged children: a social-ecologic exploration. Am J Health Promot 23, 299-308.

27. Hoyos Cillero I \& Jago R (2010) Systematic review of correlates of screen-viewing among young children. Prev Med 51, 3-10.

28. Burke V, Beilin LJ, Durkin K et al. (2006) Television, computer use, physical activity, diet and fatness in Australian adolescents. Int J Pediatr Obes 1, 248-255.

29. Taveras EM, Field AE, Berkey CS et al. (2007) Longitudinal relationship between television viewing and leisure-time physical activity during adolescence. Pediatrics 119, e314-e319.

30. Mota J, Gomes H, Almeida M et al. (2007) Active versus passive transportation to school-differences in screen time, socio-economic position and perceived environmental characteristics in adolescent girls. Ann Hum Biol 34, 273-282.

31. Johnston LD, Delva J \& O'Malley PM (2007) Sports participation and physical education in American secondary schools: current levels and racial/ethnic and socioeconomic disparities. Am J Prev Med 33, 4 Suppl., S195-S208.

32. Sirard JR \& Pate RR (2001) Physical activity assessment in children and adolescents. Sports Med 31, 439-454. 